\title{
Further studies on the influence of mycorrhizae on growth and development of micropropagated avocado plants
}

\author{
C Azcón-Aguilar 1, A Barceló 2, MT Vidal 1, G de la Viña 2 \\ 1 CSIC, Departamento de Microbiologia, Estación Experimental del Zaidín, 18008 Granada; \\ 2 Centro de Investigación y Desarrollo Agrario, 29140 Churriana, Malaga, Spain \\ (COST Meeting, 21-23 May 1992, Dijon, France)
}

\begin{abstract}
Summary - The acclimatization phase during micropropagation of avocado (Persea americana Mill) raises problems concerning the survival and development of plantlets ex vitro. Comparison of potting mixes showed that survival of plantlets was highest in a soil - sand substratum and was increased by inoculation with Glomus sp in a peat - perlite mix. Mycorrhizal infection by Glomus sp during the acclimatization process also improved development of micropropagated avocado plants growing in these 2 substrata. Inoculation with other AM fungi showed that Glomus deserticola, and to a lesser extent Glomus mosseae, improved plant development in the soil - sand mix. Mycorrhiza formation, therefore, appears to play a key role in favouring ex vitro development of micropropagated plants of avocado.
\end{abstract}

\section{Persea americana / arbuscular mycorrhizae / micropropagation}

Résumé - Étude approfondie de l'influence de mycorhizes sur la croissance et le développement de plantes d'avocat micropropagées. La phase d'acclimatation pendant la micropropagation de l'avocat (Persea americana Mili) pose des problèmes de survie et de développement des plantes ex vitro. La comparaison de mélanges de rempotage montre que la survie est la meilleure dans un substrat sable : sol et qu'elle est améliorée par l'inoculation avec un Glomus sp dans le mélange tourbe:perlite. Une infection mycorhizienne par Glomus sp pendant le processus d'acclimatation améliore également le développement des plantes d'avocat micropropagées cultivées sur ces 2 substrats. $L$ 'inoculation avec d'autres champignons AM montre que $\mathrm{G}$ deserticola, et à un moindre degré, $\mathrm{G}$ mosseae améliorent le développement des plantes dans le mélange sol:sable. La formation de mycorhizes joue un rôle clé dans le développement ex vitro de plantes micropropagées d'avocat.

Persea americana / mycorhize arbusculaire / micropropagation

\section{INTRODUCTION}

The acclimatization phase in avocado micropropagation (Persea americana Mill) raises problems concerning survival and development of the plantlets ex vitro. In a previous study, growth and nutrition of micropropagated plants of avocado were improved by post vitro inoculation with the mycorrhizal fungus Glomus fasciculatum (Vidal et al, 1992). Inclusion of soil in the potting medium appeared to stimulate mycorrhiza formation and effect. Survival, however, although enhanced by mycorrhizal inoculation, was still low. Consequently, further studies have been carried out to define a suitable potting media for plant development and for the expression of mycorrhizal effectivity, and to evaluate the effect of other arbuscular mycorrhizal (AM) fungi, in order to establish the most appropriate conditions of acclimatization for the development of the micropropagated avocado plants.

\section{MATERIALS AND METHODS}

For the micropropagation of avocado plants, juvenil shoots were excised from seedlings of the GvarAm13 rootstock, previously germinated under in vitro conditions following the procedures described by Pliego-Alfaro (1988). Cultures were grown on modified MS medium (Barceló-Muñoz et al, 1990) in a growth chamber at $25^{\circ} \mathrm{C}$ with a 16-h photoperiod and a photosynthetic photon flux of $45 \mu \mathrm{mol} \mathrm{s}-1 \mathrm{~m}^{-2}$ for 4 wk and then allowed to root for 2 additional wk 
on rooting medium as described by Pliego-Alfaro and Murashige (1987).

Two different acclimatization procedures were followed. In Experiment 1, shoots with root primordia were transferred to $500-\mathrm{ml}$ sealed glass flasks containing $200 \mathrm{ml}$ peat-perlite $(1 / 1, \mathrm{v} / \mathrm{v})$ medium. Four plantlets per flask were maintained for $4 \mathrm{wk}$ in the greenhouse (25-18 ${ }^{\circ} \mathrm{C}$ day-night, $70 \%$ relative humidity) and at the end of this period plants were individually transferred to $250-\mathrm{ml}$ plastic pots containing the tested potting mix and placed in a misting tunnel $(100 \%$ relative humidity) for an additional 4-wk period before transfer to normal greenhouse conditions. Three different growing substrata were tested: peat-perlite $(1 / 1, v / v)$ either sterilized by tindalization and non-sterile, and steam sterilized soil-sand (1/1, v/v). Glomus sp was the only mycorrhizal fungus used to test its influence on the different potting media following a factorial design.
In Experiment 2, plantlets were directly transferred from the rooting medium in test tubes into the open pots containing a sterile soil - sand mix, which gave best results in Experiment 1, and placed in the misting tunnel as in Experiment 1. The effect of $G$ deserticola and $G$ mosseae on plant development was studied.

In both experiments, and after the 4-wk period in the misting tunnel, plants were transferred to normal greenhouse conditions $\left(18-25^{\circ} \mathrm{C}\right.$ day-night, $70 \%$ relative humidity and natural photoperiod).

In all cases, mycorrhizal inoculum was added to the plants when transferred to the plastic pots. It consisted of $1 \mathrm{~g}$ (fresh weight) per plant of clean mycorrhizal onion roots, placed close to the root system. Control plants received filtered leachates of the mycorrhizal inoculum, free from mycorrhizal propagules to compensate for the presence of free-living microorganisms associated with the inoculum.

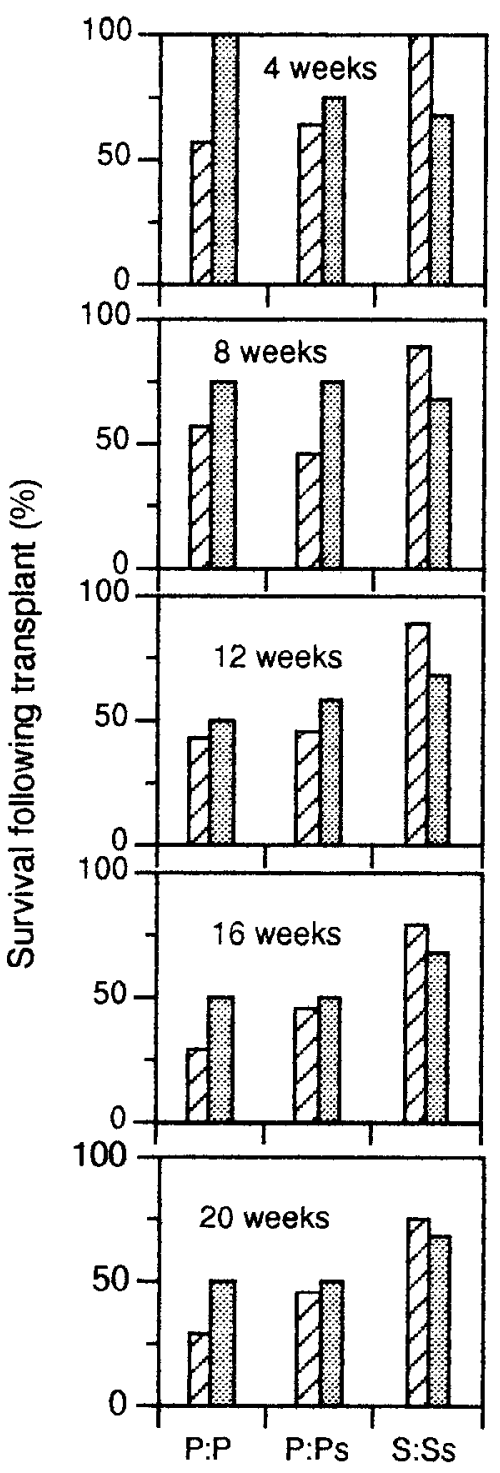

Substratum

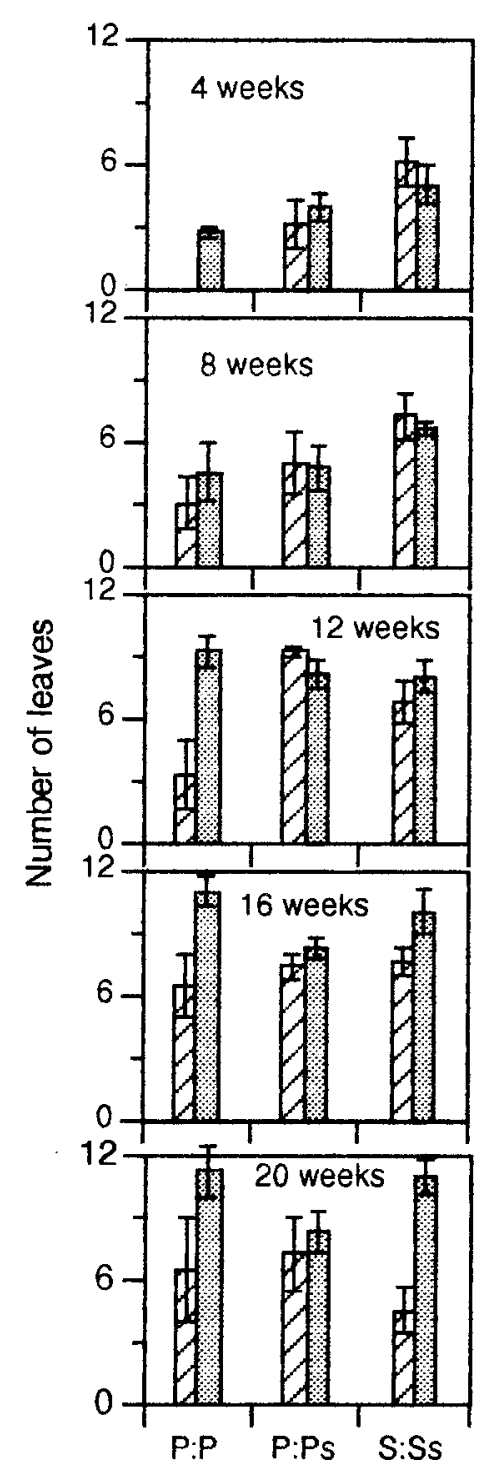

Substratum

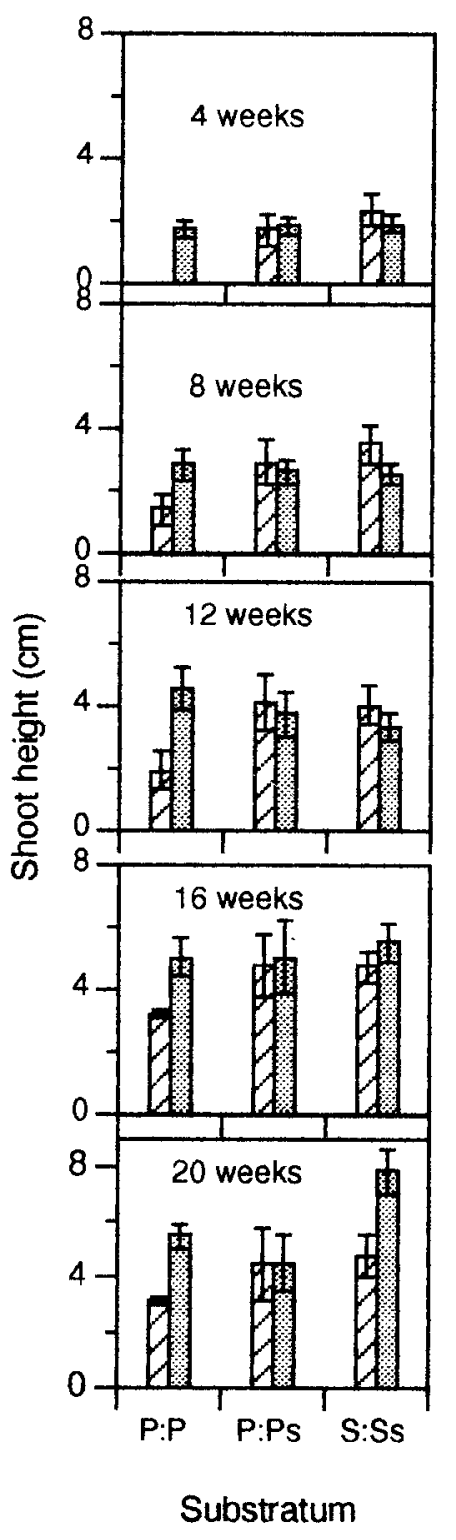

Fig 1. Effect of different potting mixes and of inoculation with Glomus sp on survival, number of leaves and shoot height of micropropagated plants of avocado following transplanting (P:P, peat:perlite; P:Ps, sterile peat:perlite; S:Ss, sterile soil: sand; $\square$ control uninoculated plants; mycorrhizal plants). Bars represent SE of means. 
Twelve and 13 replicate plants per treatment were used in Experiment 1 and 2 respectively. Survival of plants, number of leaves and shoot height were determined at different times following transplanting, and standard errors were calculated.

\section{RESULTS}

\section{Experiment 1}

Survival of the plantlets ex vitro (fig 1) was higher in the soil-sand mix and in Glomus spinoculated plants growing in the peat-perlite mix. Glomus sp did not produce consistent effects on the development of plants growing in the sterile peat-perlite substratum. However, mycorrhizal inoculation significantly improved shoot height and number of leaves of plants growing in the nonsterile peat-perlite and sterile soil-sand mixes. These effects were evident after $12 \mathrm{wk}$ growth. Since a higher rate of survival of the plants was obtained in the soil-sand mix, this substratum was selected for the second experiment.

\section{Experiment 2}

The acclimatization conditions used in this experiment gave increased survival rates of plantlets, reaching values of $85 \%$ after 16 wk growth in all treatments (fig 2). Mycorrhizal inoculation had no effect on the survival of the plants, but improved plant development. Glomus deserticola and to a lesser extent Glomus mosseae increased shoot height, leaf number and vigour of the plantlets (fig 2).

\section{DISCUSSION AND CONCLUSION}

The present results confirm that mycorrhizal inoculation by different $A M$ fungi is effective in promoting plant growth and development of micropropagated avocado (Vidal et al, 1992). They also show that it is important to define the potting mix and endomycorrhizal fungus to be used if maximum benefits are to be gained after transplanting ex vitro. Although plants were not analysed for mineral content, it is probable that this effect is, at least partially, due to the well-known mycorrhizal activity in increasing mi-
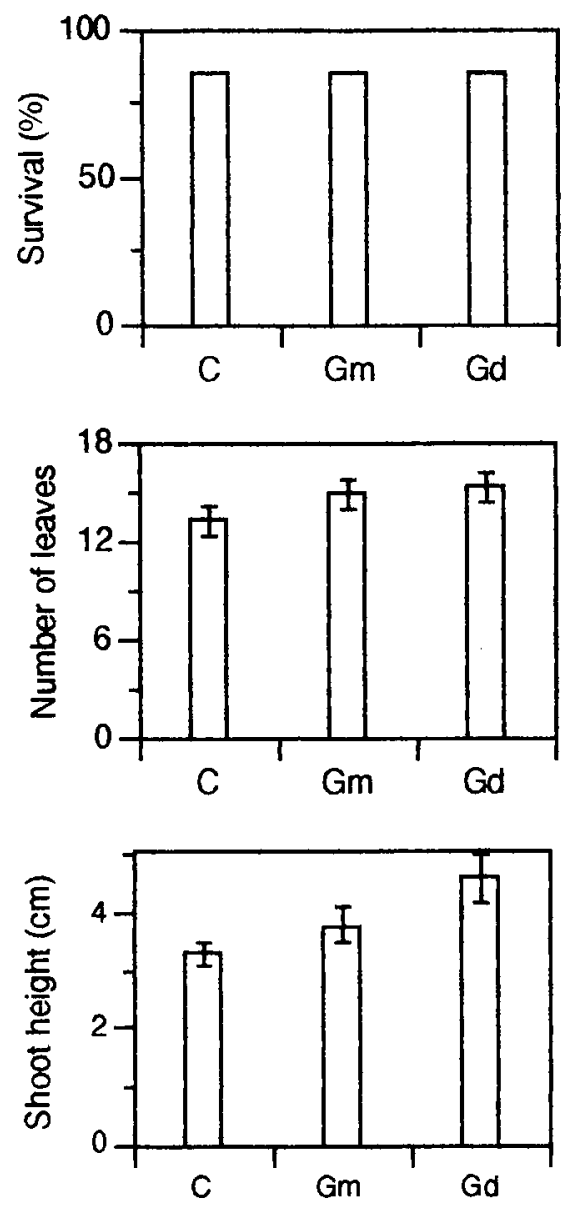

Treatments

Fig 2. Effect of the inoculation with different arbuscular mycorrhizal fungi on survival and development of micropropagated avocado plants after 16 wk growth following transplanting (C, uninoculated control; Gm, Glomus mosseae; Gd, Glomus deserticola). Bars represent SE of means.

neral uptake by plants. However, mycorrhizal inoculation has also been reported to increase the production of lateral roots in mycorrhizal, micropropagated grapevine plants as compared to uninoculated ones (Schellenbaum et al, 1991). Thus, a morphogenetic effect of the AM fungi on the root system of micropropagated plants of avocado cannot be excluded. Rooting of micropropagated avocado is a problem and therefore possible effects of endomycorrhizal formation on root morphogenesis requires further research.

In conclusion, mycorrhizal formation appears to play an important role in assuring satisfactory ex vitro development of micropropagated plants of avocado. 


\section{ACKNOWLEDGMENT}

This study was supported by CICyT-Spain (Project AGR 91-0605-C02-01).

\section{REFERENCES}

Barceló-Muñoz A, Pliego-Alfaro F, Barea JM (1990) Micropropagación de aguacate (Persea americana Mill) en fase juvenil. Proc 3rd Spanish Conf Hortic Sci. Tenerife, Spain, oct 1988

Pliego-Alfaro F (1988) Development of an in vitro rooting bioassay using juvenile-phase stem cuttings of Persea americana Mill. J Hortic Sci 63, 295-301

Pliego-Alfaro F, Murashige T (1987) Possible rejuvenation of adult avocado by graftage onto juvenile rootstocks in vitro. HortSci 22, 1321-1324

Schellenbaum L, Berta G, Ravolanirina F, Tisserant B, Gianinazzi S, Fitter AH (1991) Influence of endomycorrhizal infection on root morphology in a micropropagated woody plant species (Vitis vinifera $\mathrm{L}$ ). Ann Bot 68, 135-141

Vidal MT, Azcón-Aguilar C, Barea JM, Pliego-Alfaro F (1992) Mycorrhizal inoculation enhances growth and development of micropropagated plants of avocado. HortSci 27, 785-787 